\title{
IMPROVEMENT OF POWER ELECTRONIC STRUCTURE CHARACTERISTICS USING SiC TECHNOLOGY - OVERVIEW
}

This paper is dedicated to the recent unprecedented boom of SiC electronic technology. The contribution deals with a brief survey of those properties. In particular, the differences (both good and bad) between SiC electronics technology and well-known silicon VLSI technology are highlighted. Projected performance benefits of SiC electronics are given for several large-scale applications at the end of the contribution. The basic properties of SiC material were discussed already at the beginning of 1980's, also in our work place [1].

\section{Introduction}

Silicon carbide $(\mathrm{SiC})$ based semiconductor electronic devices and circuits are presently being developed for the use in high-temperature, high-power, and/or high-radiation conditions under which conventional semiconductors cannot adequately perform. Silicon carbide's ability to function under such extreme conditions is expected to enable significant improvements to a far-ranging variety of applications and systems. These range from greatly improved high-voltage switching for energy savings in public electric power distribution and electric motor drives to more powerful microwave electronics for radar and communications to sensors and controls for cleaner-burning more fuel-efficient jet aircraft and automobile engines. In the particular area of power devices, theoretical appraisals have indicated that $\mathrm{SiC}$ power MOSFET's and diode rectifiers would operate over higher voltage and temperature ranges, have superior switching characteristics, and yet have die sizes nearly 20 times smaller than correspondingly rated silicon-based devices. However, these tremendous theoretical advantages have yet to be realized in experimental $\mathrm{SiC}$ devices, primarily due to the fact that $\mathrm{SiC}$ 's relatively immature crystal growth and device fabrication technologies are not yet sufficiently developed to the degree required for reliable incorporation into most electronic systems. The widely spread usage of power semiconductors manufactured of $\mathrm{SiC}$ is one of the most promising developments at this market today. Because of the outstanding performance of this new material high voltage blocking active switches are under investigation [1], [7], [11].

This paper briefly surveys the $\mathrm{SiC}$ semiconductor electronics technology. In particular, the differences (both good and bad) between $\mathrm{SiC}$ electronics technology and well-known silicon VLSI technology are highlighted. Projected performance benefits of SiC electronics are highlighted for several large-scale applications. Key crystal growth and device-fabrication issues that presently limit the performance and capability of high temperature and/or high power $\mathrm{SiC}$ electronics are identified.

\section{SiC Material Fundamental Properties}

$\mathrm{SiC}$ is a material with outstanding properties for power semiconductor application. Beside research activities including different power semiconductor switch types, unipolar JFET devices for blocking voltage of more than $1200 \mathrm{~V}$ are applicable as samples promising switching loss reduction above all [11].

In comparation with a similar table in [1] one can see that, the new material $4 \mathrm{H}-\mathrm{SiC}$ with energy bandgap $3.2 \mathrm{eV}$ has been developed and is mostly used in applications (see below in chapters 4 and 5).

The wide bandgap energy and low intrinsic carrier concentration of $\mathrm{SiC}$ allow $\mathrm{SiC}$ to maintain semiconductor behavior at much higher temperatures than silicon, which in turn permits $\mathrm{SiC}$ semiconductor device functionality at much higher temperatures than silicon. As discussed in basic semiconductor textbooks [1], semiconductor electronic devices function in the temperature range where intrinsic carriers are negligible so that conductivity is controlled by intentionally introduced dopant impurities. Furthermore, the intrinsic carrier concentration ni is a fundamental prefactor to well-known equations governing undesired junction reverse-bias leakage currents [7].

As temperature increases, intrinsic carriers increase exponentially so that undesired leakage currents grow unacceptably large, and eventually at still higher temperatures, the semiconductor device operation is overcome by uncontrolled conductivity as intrinsic carriers exceed intentional device dopings. Depending upon a specific device design, the intrinsic carrier concentration of silicon generally confines silicon device operation to junction temperatures less than $300{ }^{\circ} \mathrm{C}$. SiC's much smaller intrinsic carrier concentration theoretically permits device operation at junction temperatures exceeding $800{ }^{\circ} \mathrm{C}$, and $600{ }^{\circ} \mathrm{C} \mathrm{SiC}$ device operation has been experimentally demonstrated on a variety of $\mathrm{SiC}$ devices.

\footnotetext{
* B. Dobrucký, P. Špánik, R. Šul

Faculty of Electrical Engineering, Dept. of Mechatronics and Electronics, University of Zilina,

E-mail: branislav.dobrucky@fel.utc.sk,pavol.spanik@fel.utc.sk, robert.sul@fel.utc.sk
} 


\begin{tabular}{|c|c|c|c|c|c|}
\hline Property & Silicon & GaAs & $4 \mathrm{H}-\mathrm{SiC}$ & $6 \mathrm{H}-\mathrm{SiC}$ & 3C-SiC \\
\hline Bandgap $[\mathrm{eV}]$ & 1.1 & 1.42 & 3.2 & 3.0 & 2.3 \\
\hline Relative Dielectric Constant & 11.9 & 13.1 & 9.7 & 9.7 & 9.7 \\
\hline Breakdown Field $N D=10^{17} \mathrm{~cm}^{-3}[\mathrm{MV} / \mathrm{cm}]$ & 0.6 & 0.6 & $\begin{array}{l}\text { //c-axis: } 3.0 \\
\text { //c-axis: } 3.2\end{array}$ & | c-axis: $>1$ & $>1.5$ \\
\hline Thermal Conductivity $[\mathrm{W} / \mathrm{cmK}]$ & 1.5 & 0.5 & $3-5$ & $3-5$ & $3-5$ \\
\hline Intrisic Carrier Concentration $\left[\mathrm{cm}^{-3}\right]$ & 1010 & $1.8 \times 106$ & $\sim 10^{-7}$ & $\sim 10^{-5}$ & $\sim 10$ \\
\hline Electron Mobility@ $N D=10^{16} \mathrm{~cm}^{-3}\left[\mathrm{~cm}^{-2} / \mathrm{Vs}\right]$ & 1200 & 6500 & $\begin{array}{l}\text { //c-axis: } 800 \\
\text { | c-axis: } 800\end{array}$ & $\begin{array}{l}\text { //c-axis: } 60 \\
\text { | c-axis: } 400\end{array}$ & 750 \\
\hline 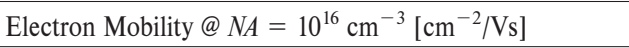 & 420 & 320 & 115 & 90 & 40 \\
\hline Saturated Electron Velocity $\left[10^{17} \mathrm{~cm} / \mathrm{s}\right]$ & 1.0 & 1.2 & 2 & 2 & 2.5 \\
\hline Donor Dopants \& Shallowest Ionization Energy [meV] & $\begin{array}{c}\text { P: } 45 \\
\text { As: } 54\end{array}$ & Si: 5.8 & $\begin{array}{l}\text { P: } 45 \\
\text { As: } 80\end{array}$ & $\begin{array}{l}\text { P: } 85 \\
\text { As: } 80\end{array}$ & $\mathrm{~N}: 50$ \\
\hline Acceptor Dopants \& Shallowest Ionization Energy [meV] & B: 45 & $\begin{array}{c}\mathrm{Be}, \mathrm{Mg}, \\
\mathrm{C}: 28\end{array}$ & $\begin{array}{l}\text { Al: } 200 \\
\text { B: } 300\end{array}$ & $\begin{array}{l}\mathrm{Al}: 200 \\
\mathrm{~B}: 300\end{array}$ & Al: 270 \\
\hline
\end{tabular}

The structure of $6 \mathrm{H}-\mathrm{SiC}$ new material is shown in Fig. 1.

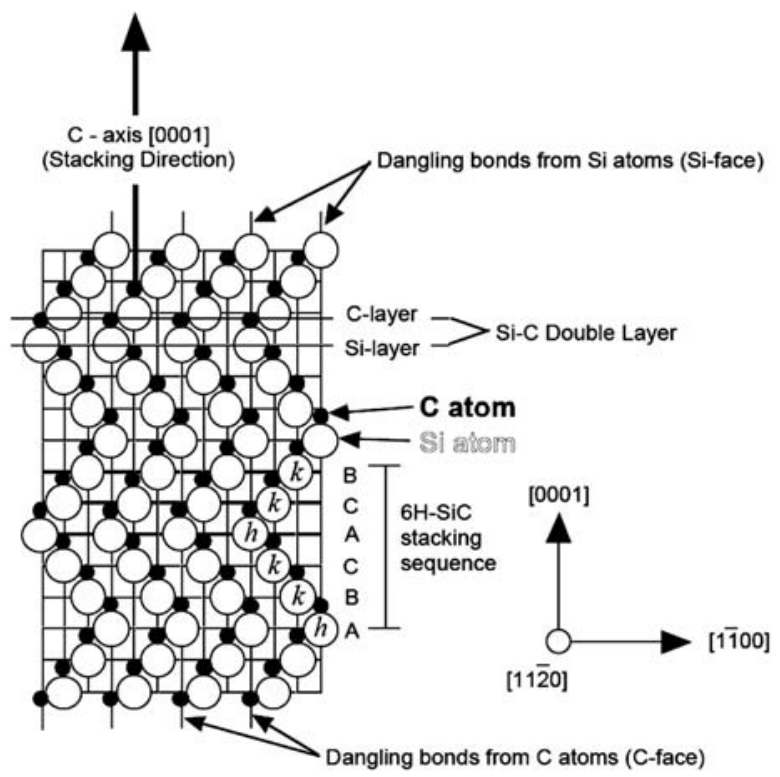

Fig. 1 Schematic cross-section [(1120) plane] of the 6H-SiC polytype [7]

\section{Comparison of conduction characteristics of $\mathrm{Si}$ and $\mathrm{SiC}$}

While SiC's smaller on-resistance and faster switching helps minimize energy loss and heat generation, SiC's higher thermal conductivity enables more efficient removal of waste heat energy from the active device (see Fig. 2). As heat energy radiation efficiency increases greatly with an increasing temperature difference between the device and the cooling ambient, SiC's ability to operate at high junction temperatures permits much more efficient cooling to take place, so that heatsinks and other device-cooling hardware (i.e., fan cooling, liquid cooling, air conditioning, etc.) typically needed to keep high-power devices from overheating can be made much smaller or even eliminated.

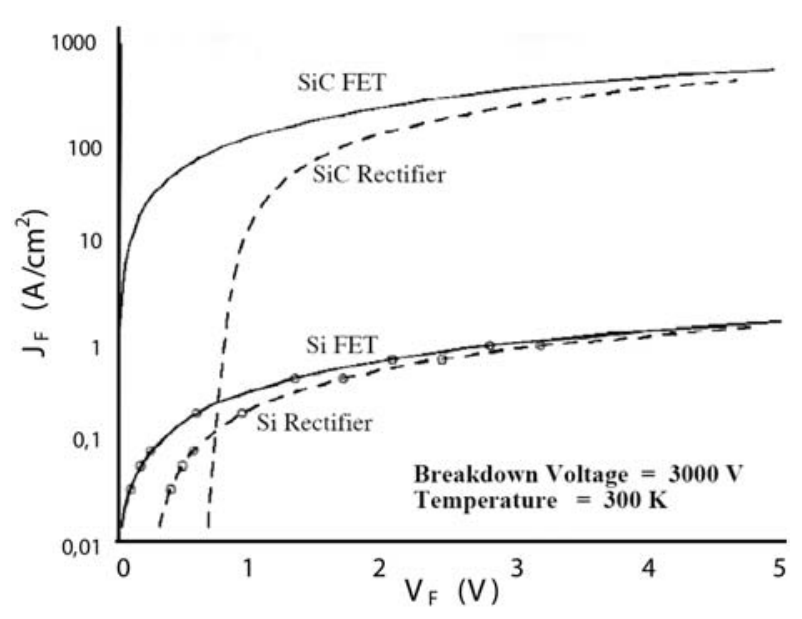

Fig. 2 Simulation experiment for forward conduction characteristics of ideal $\mathrm{Si}$ and $\mathrm{SiC} 3000 \mathrm{~V}$

While so far discussions have been focused on high-power switching for power conversion [10], many of the same arguments can be applied to devices used to generate and amplify RF signals used in radar and communications applications. In particular, the high breakdown voltage and high thermal conductivity coupled with high carrier saturation velocity allow $\mathrm{SiC}$ microwave devices to handle much higher power densities than their silicon or GaAs RF counterparts, despite SiC's disadvantage in low-field carrier mobility. 


\section{Advantages of $\mathrm{SiC}$ structure compared with Si material}

As mentioned in Tab. 1, SiC is a wide-bandgap semiconductor, and this property of $\mathrm{SiC}$ is expected to yield greatly superior power electronics devices once processing and fabrication issues with this material are solved. Some of the advantages of $\mathrm{SiC} \mathrm{com-}$ pared with Si based power devices are as follows:

- SiC-based power devices have higher breakdown voltages (5 to 30 times higher than those of $\mathrm{Si}$ ) because of their higher electric breakdown field.

- $\mathrm{SiC}$ devices are thinner, and they have lower on-resistances. The substantially higher breakdownvoltage for $\mathrm{SiC}$ allows higher concentrations of doping and consequently a lower series resistance. For lowbreakdown voltage devices $(\sim 50 \mathrm{~V}), \mathrm{SiC}$ unipolar device on-resistances are around 100 times less; and at higher breakdown voltages $(\sim 5000 \mathrm{~V})$, they are up to 300 times less. With lower Ron, $\mathrm{SiC}$ unipolar power devices have lower conduction losses and therefore higher overall efficiency.

- $\mathrm{SiC}$ has a higher thermal conductivity and thus a lower junction-to-case thermal resistance, $R t h-j c$. This means heat is more easily conducted away from the device junction, and thus the device temperature increase is slower.

- $\mathrm{SiC}$ can operate at high temperatures because of its wider bandgap. $\mathrm{SiC}$ device operation at up to $600{ }^{\circ} \mathrm{C}$ is mentioned in the literature. Most Si devices, on the other hand, can operate at a maximum junction temperature of only $180{ }^{\circ} \mathrm{C}$.

- Forward and reverse characteristics of $\mathrm{SiC}$ power devices vary only slightly with temperature and time; therefore, $\mathrm{SiC}$ devices are more reliable.

- SiC-based devices have excellent reverse recovery characteristics. With less reverse recovery current, the switching losses and electromagnetic interference (EMI) are reduced and there is less or no need for snubbers.

- $\mathrm{SiC}$ is extremely radiation hard; i.e., radiation does not degrade the electronic properties of $\mathrm{SiC}$. [8]

\section{Possibilities of application of $\mathrm{SiC}$ materials in power electronic systems}

The structure of SiC Vertical Junction Field Effect Transistor is given in Fig. 3. Properties of this structure are as follows:

- Very high switchin speed

- High T capability (PN-isolation)

- Fast \& robust PN body diode

- Volume mobility in the channel

- Doping: channel $>$ drift region

- Suitable up to 3 - $4 \mathrm{kV}$

- Lowest $\mathrm{R}_{\text {on }}$ (today)

- No need for an external freewheeling diode

Cascode connection - basic connection V-JFET transistor (Fig. 4)

- $80 \mathrm{~m} \Omega$ ON-resistance $\left(25^{\circ} \mathrm{C}\right)$ includes low voltage Si-MOSFET

- High short circuit capability

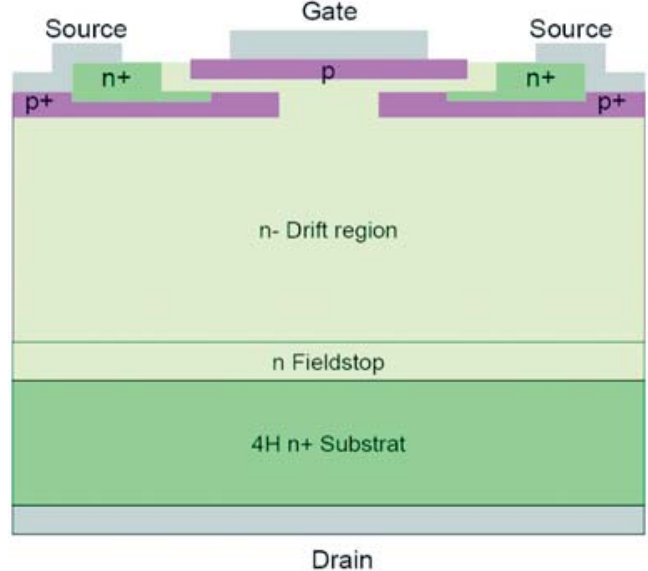

Fig. 3 Structure of SiC V-JFET

- Power almost totally on SiC V-JFET

- High T capability

Schematic diagram of the SiC Schottky diode structure, showing the field oxide, the overlapping metal electrode, and the epi-layer drift region (Fig. 5).

- Low-switch losses

- Breakdown voltages of 1000 to $1100 \mathrm{~V}$

- High-Temperature Performance (over $300^{\circ} \mathrm{C}$ )

Main applications:

- Power electronics

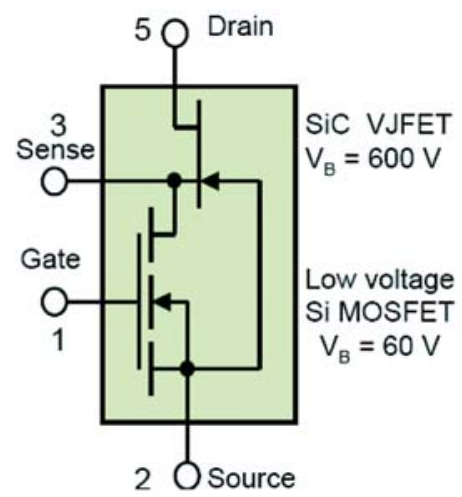

Fig. 4 Cascode SiC V-JFET + MOS FET

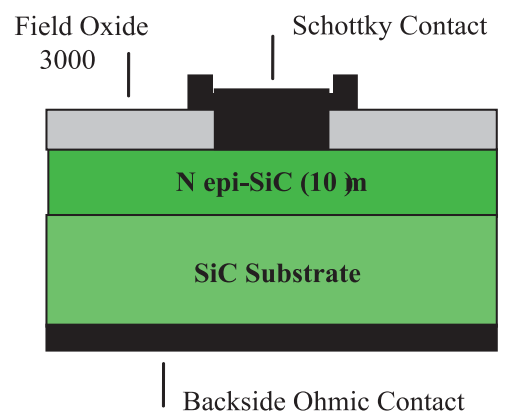

Fig. 5 Structure of SiC Schottky diode 
Power supplies

Power converters

PFC

UPS

- Transmission and Distribution

Power active filters

FACTs

- Production of electric energy

Photovoltaic systems

Marine applications

Wind-power plant

- Motor drives

AC, DC drives

SRM, SMPM drives

- Automotive

- Power amplifiers

- Defence,

- Aviation,

- Space program

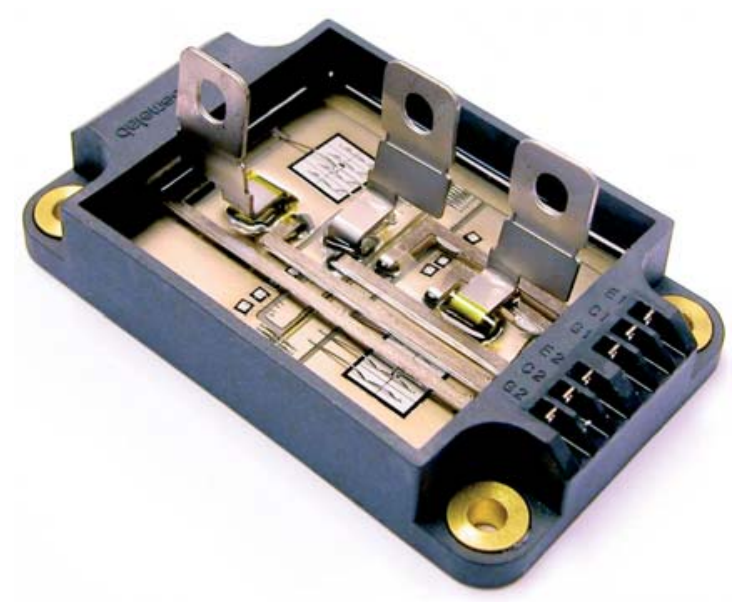

Fig. 6 SEMLab prototype 1200 V hybrid Si IGBT/SiC Schottky diode module [2]

Companies developing $\mathrm{SiC}$ devices:

- Diodes (Schottky/PIN) - Cree, Infineon/SiCED, Dynex, EcoTron, GF, Mitsubishi,

Rohm, Semisouth, Int. Rectifier, Rockwell, STMicroelectronics ...

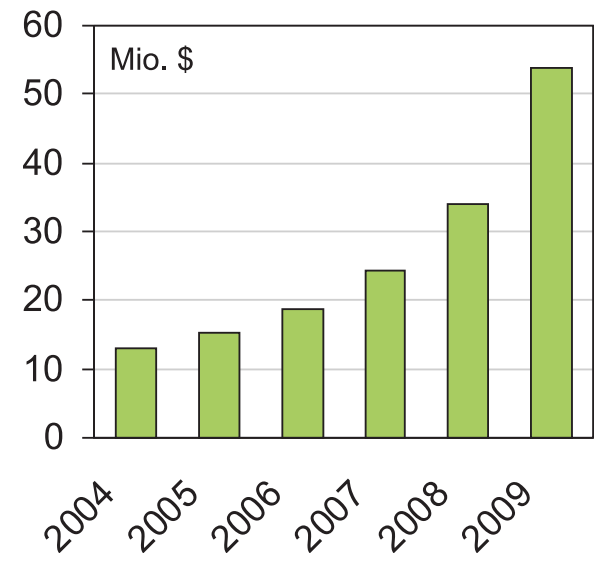

Fig. 72004 - 2009 World market for SiC devices

- Transistors (JFET/SIT) - Northrop, Cree, Infineon/SiCED, Semisouth, Rockwell,

Hitachi, Intrisic, Toshiba, Fairchild, Mitsubishi, Rohm, Philips, Nippondenso ...

- Thyristors - Cree, GE

\section{Conclusions}

The new possibilities and characteristics of the $\mathrm{SiC}$ structure are discussed and reported in the paper.

The new survey [17] forecasts that the world market for Schottky diodes and power transistors will grow from $\$ 13$ million in 2004 to over $\$ 53$ million in 2009. Schottky diodes, supplied by US Cree Company and by Infineon in Europe, will penetrate the microelectronics market at a much higher rate than transistors, which are less mature. Rockwell Scientific and Cree supply SiC MOSFETs, and another 15 companies, mostly major chip manufacturers, are working on further development of these transistors.

\section{Acknowledgment}

The authors wish to thank to the Ministry of Education of the Slovak Republic for the financial support of the project „Improvement of quality and exploitation of el. energy for traction and general applications" No. 2003 SP 51/028 09 00/028 09 05-2003, and also to the Scientific Grant Agency for the project No. $1 / 0178 / 03$.

\section{References}

[1] DOBRUCKÝ, B., RÁČEK, V., ŠPÁNIK, P., GUBRIC, R.: Power Semiconductors Structures (in Slovak), EDIS Editor Zilina (SK),1995

[2] LOCATElLI, M. L., GAMAL, S. H., CHANTE, J. P.: Semiconductor Material for High Temperature Power Devices, EPE Journal (4) 1994, No. 1, pp. 43-46

[3] GRECKI, M., NAPIERALSKI, A.: Static Induction Transistor - A New High Speed Power Device. In: Proc. PEMC'94, Warsaw, Sept. 1994, Vol. 2, pp. 836-841 
[4] JANUSZEWSKY, S.: Power Semiconductors Devices- State of Art \& Recent Trends. In. Proc. PEMC '94, Warsaw, Sept. 1994, Vol. 2, pp. 861-866

[5] HEUMANN , K.: Trends in Semiconductor Devices and Impact on Power Electronics. In Proc. PEMC'94, Warsaw, Sept. 1994, Vol.2, pp. 1288-1299

[6] BENDA, V.: Power Semiconductors and Integrated Structures. ČVUT Editor, Prague (CZ), 1994

[7] NEUDECK, P. G.: SiC Technology, NASA Lewis Research Center, Cleveland USA, 1998,

[8] TOLBERT, L. M., OZPINECI, B., ISLAM, S. K., PENG, F. Z.: Impact of SiC Power Electronic Devices for Hybrid Electric Vehicles, SAE 2002 Transactions, Journal of Passenger Cars: Electronic and Electrical Systems, 2003, pp. 765-771

[9] STEPHANI, D.: The Industrial Utilization of SiC Power Devices - Aspects and Prospects, Lecture given at the Workshop on Future Electron Devices (FED), Yokohama (JP), March 2003

[10] STEPHANI, D.: Today's and tomorrow's industrial utilization of silicon carbide semiconductor power devices, Revue de l'Électricité et de l'Électronique, Feb 2004, pp. 23-24

[11] DOMES, D., HOFMANN, W., LUTZ, J.: A First Loss Evaluation using a vertical SiC-JFET and a Conventional Si-IGBT in the Bidirectional Matrix Converter Switch Topology, of EPE'05 Conf., Dresden (DE), Sept. 2005, (CD-ROM)

[12] www.semlab.com

[13] www.infineon.com

[14] http://nina.ecse.rpi.edu/shur/SiC

[15] www.iem.ing.tu-bs.de/paper/2004/kohi_04.htm

[16] www.siced.de

[17] www.wtc-consult.de 